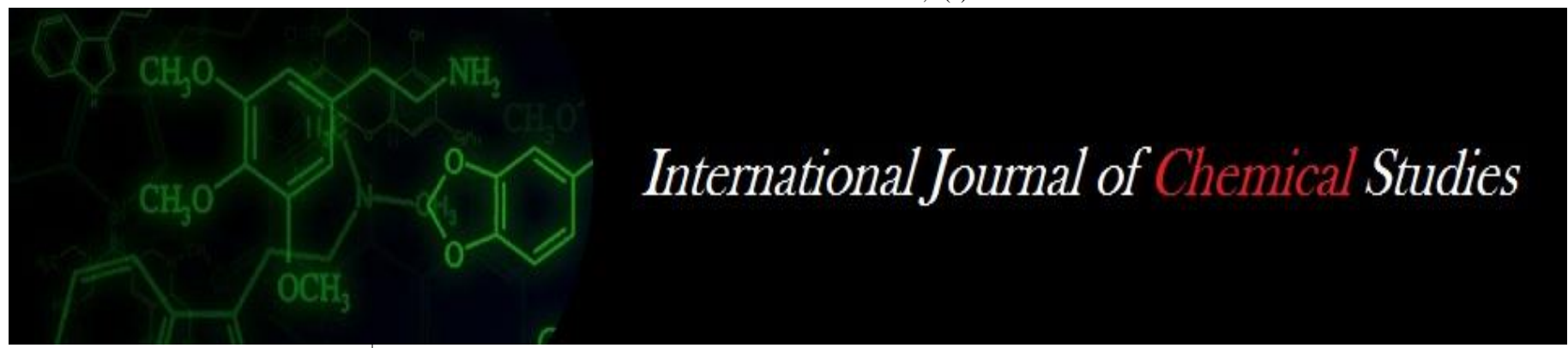

P-ISSN: 2349-8528

E-ISSN: 2321-4902

www.chemijournal.com

IJCS 2020; 8(2): 588-590

(C) 2020 IJCS

Received: 16-01-2020

Accepted: 18-02-2020

\section{Premavalli K}

Postgraduate Research Institute in Animal Sciences, Tamil Nadu Veterinary and Animal Sciences University, Kattupakkam, Tamil Nadu, India

\section{Sundaresan A}

Directorate of Centre for Animal Production Studies, Tamil Nadu Veterinary and Animal Sciences University, Chennai, Tamil Nadu, India

\section{Omprakash AV}

Directorate of Centre for Animal Production Studies, Tamil Nadu Veterinary and Animal Sciences University, Chennai, Tamil

Nadu, India

Selvan ST

Department of Poultry Science, Madras Veterinary College, Tamil Nadu Veterinary and Animal Sciences University, Chennai, Tamil Nadu, India

\section{Hatching performance of breeder turkey as influenced by parental age}

\author{
Premavalli K, Sundaresan A, Omprakash AV and Selvan ST
}

DOI: https://doi.org/10.22271/chemi.2020.v8.i2i.8829

\begin{abstract}
A total of 7452 hatching eggs collected from 29 to 72 weeks of age of turkey breeders were analyzed. Parental age exhibited a highly significant $(p<0.01)$ influence on mean per cent total hatchability, fertile hatchability and total embryonic mortality and non significant $(p \geq 0.05)$ influence on per cent fertility. Significantly $(p<0.01)$ higher per cent total hatchability, fertile hatchability and lower mean per cent total embryonic mortality were observed as the age of the bird advanced from 29 to 52 and 65 to 72 weeks except during 53-64 weeks. It can be concluded that significantly better hatching performance were recorded from the eggs laid by turkey breeder hen during 29 to 52 and 65 to 72 weeks of age and hence, it is advisable to collect hatching eggs from 29 weeks to 52 weeks of age of turkey breeders to obtain higher hatchability performance.
\end{abstract}

Keywords: Turkey breeders, hatching performance, parental age

\section{Introduction}

The primary objective of turkey (Meleagris gallopavo) breeder farm is to produce more number of quality hatching eggs so as to increase the number of quality poults produced per turkey breeder female/year. Hatchability depends on good quality fertile eggs from the breeder farm and incubation environment at the hatchery thus fertility and hatchability forms the basis of any hatchery operation. Factors that affect hatchability include strain, health, nutrition and age of the flock, egg size, weight and quality, egg storage duration and conditions (King'ori, 2011) ${ }^{[1]}$. Many researchers reported that the age of the breeder parents had significant effect on the reproductive performance (Leeson, 2003 ${ }^{[2]}$; Koppenol et al. 2015 $5^{[3]}$ )). In general, older flocks have lower fertility and hatchability than younger flock. The age of the breeder is thus an important parameter to take into account when collecting hatching eggs for incubation to obtain good hatchability. Hence, the aim of the present study is to find out the influence of age of the parent on hatching performance of turkey.

\section{Materials and Methods}

A biological trial was conducted at the Poultry Research Station, Tamil Nadu Veterinary and Animal Sciences University, Chennai, to examine the effect of age of the parent on hatching performance of turkey. Turkey breeder birds were maintained with standard managemental and nutritional conditions. A total of 7452 hatching eggs collected from 29 to 72 weeks of age of turkey breeders maintained with a sex ratio of 1:4 under deep litter system of management were stored for 7 days at $15^{0}{ }_{-} 18^{\circ} \mathrm{C}$ and $75 \% \mathrm{RH}$ in the egg cold storage room. After storage, hatching eggs were moved to ambient temperature, kept for one hour and then set for incubation. The setter was maintained at a temperature of $99.5^{\circ} \mathrm{F}$ and relative humidity of $55 \%$ for first 24 days of incubation. The eggs were turned at hourly interval by an automatic turner. On $25^{\text {th }}$ day of incubation, the eggs were transferred to hatcher, in which $98.5^{\circ} \mathrm{F}$ temperature and $72 \%$ relative humidity were maintained. Hatching started on day 27 and was completed by the end of day 28 of incubation. Number of poults hatched was recorded and unhatched eggs were examined for early and late embryonic mortality. From the data, total hatchability, fertile hatchability and embryonic mortality were calculated. The data were analyzed statistically as per Snedecor and Cochran (1994) ${ }^{[4]}$. 


\section{Results and Discussion}

The results of the effect of hatching performance of breeder turkey as influenced by parental age are presented in table 1 . The parental age had a significant $(P<0.01)$ influence on total hatchability, fertile hatchability and embryonic mortality in turkey.

The overall mean per cent fertility was $73.45 \pm 1.05$. Parental age did not have any significant $(p \geq 0.05)$ influence on mean per cent fertility. The mean per cent fertility recorded in this study was lower than the values reported by Anna anandh et al. (2012) ${ }^{[5]}$ and Premavalli et al. $\left(2018^{[6]}\right)$ which may be due to different turkey strains, rearing systems and pre-incubation storage period. However, Bakst et al. (1994) ${ }^{[7]}$ reported that the younger hens could store more spermatozoa in its sperm storage tubules compared to the older hens and the fertile eggs from turkey hens depend on the spermatozoa entering the oviducts sperm storage tubules. Fertility of an egg is affected by factors directly related to the laying hen such as her ability to mate successfully, store sperm, ovulate an egg cell and finally produce a suitable environment for the formation and development of the embryo and fertility also depends on the ability of cock to mate successfully, quantity and quality of semen deposited (Brillard 2003) ${ }^{[8]}$.

The parental age exhibited a highly significant $(p<0.01)$ influence on mean per cent total hatchability and fertile hatchability. The overall mean per cent total hatchability and fertile hatchability recorded in this study was $47.35 \%$ and $63.79 \%$ respectively. Significantly $(p<0.01)$ higher mean per cent total hatchability and fertile hatchability were observed as the age of the bird advanced from 29 to 52 and 65 to 72 weeks with a dip during 53-64 weeks. Premavalli et al. (2018) [6] reported that the overall mean per cent total hatchability $49 \%$ for the eggs stored for 1-7 days in turkey; the overall mean fertile hatchability was $57.9 \%$ which was significantly $(P<0.05)$ higher in Nandanam Turkey - 1 (65.4\%) than Beltsville Small White $(53.5 \%)$. The decline in hatchability with advancement of age upto 52 weeks of age due to increased total embryonic mortality as observed in this study is in agreement with the earlier results reported by Tona et al.
(2001) ${ }^{[10]}$ and Koppenol et al. (2015) ${ }^{[5]}$. Mean per cent hatchability on total egg set observed in our study was higher than the value (37.65\%) reported by Khan et al. (2013) ${ }^{[9]}$ and lower than the value $(64.15 \%)$ reported by Ozcelik et al. (2006) ${ }^{[11]}$ and Anna Anandh et al. (2012) ${ }^{[5]}$ in Broad Breasted Bronze turkeys $(81.00 \%)$ which might be due to differences in turkey strains, rearing systems and pre-incubation storage periods used in their studies.

The overall mean per cent total embryonic mortality was $36.22 \%$ on fertile eggs basis which includes dead germs $(19.98 \%)$ and dead in shell (16.24\%). Highly significant $(p<0.01)$ influence of parental age on mean per cent dead germs and total embryonic mortality but not on dead in shell of turkey eggs was observed in this study. Significantly $(p<0.01)$ lower mean per cent total embryonic mortality was recorded from 29 to 52 and 65 to 72 weeks except during 53 64 weeks of age, coinciding with increase in total and fertile hatchability in turkeys. This is in agreement with the earlier findings of Yilmaz-Dikmen and Sahan (2009) ${ }^{[12]}$ and Koppenol (et al. 2015) [3], who stated that the embryonic mortality differs between different hen ages in different poultry species. Okur et al. (2018) ${ }^{[13]}$ also found that that the breeder age affected early embryonic mortality and hatchability of fertile eggs $(P<0.05)$ and the early embryonic mortality values of young flocks was lower than older one and accordingly hatchability of fertile eggs was higher. Mean per cent embryonic mortality observed in this study was lower than the value reported by Anna anandh et al (2012) ${ }^{[5]}$; Khan et al. (2013) [9] and Premavalli et al. (2018) ${ }^{[6]}$. Eggs from older hens are associated with larger size and thinner shells with higher porosity, which promotes gas and water diffusion. This affects early embryonic mortality due to dehydration, resulting in a lower hatchability (Tona et al. 2001) ${ }^{[10]}$. Variations in embryonic mortality may be due to imbalanced nutrition, stressful conditions the parent flock was exposed to, or any other fault in incubation and hatching requirements/equipments. These results are presumably related to changes in egg quality traits by female breeder aging as reported by Latour et al. (1998) ${ }^{[14]}$.

Table 1: Mean \pm S.E hatching performance of breeder turkey as influenced by parental age

\begin{tabular}{|c|c|c|c|c|c|c|c|c|c|}
\hline \multirow[b]{2}{*}{ Treatments } & \multirow{2}{*}{$\begin{array}{c}\text { Age of the } \\
\text { bird } \\
\text { (wks) }\end{array}$} & \multirow{2}{*}{$\begin{array}{l}\text { No. of } \\
\text { eggs set }\end{array}$} & \multirow[b]{2}{*}{ Total chicks } & \multirow{2}{*}{ Fertility $\%$ NS } & \multicolumn{2}{|c|}{ Hatchability \% } & \multirow{2}{*}{$\begin{array}{c}\text { Dead } \\
\text { Germs\%** }\end{array}$} & \multirow{2}{*}{$\begin{array}{l}\text { Dead in } \\
\text { Shell\% } \%^{\mathrm{NS}}\end{array}$} & \multirow{2}{*}{\begin{tabular}{|c} 
Total Embryonic \\
mortality\%***
\end{tabular}} \\
\hline & & & & & TES $* *$ & FES $* *$ & & & \\
\hline$T-1$ & $29-32$ & 675 & 388 & 74.0 & 57.17 & 77.38 & $7.22^{\mathrm{a}} \pm 1.11$ & $15.40 \pm 2.01$ & $22.62^{a} \pm 2.68$ \\
\hline$T-2$ & $33-36$ & 1422 & 663 & 68.56 & $46.46^{\mathrm{a}}$ & $68.17^{\mathrm{a}} \pm 4.67$ & $14.75^{\mathrm{a}} \pm 2.72$ & $17.09 \pm 5.20$ & \\
\hline $\mathrm{T}-3$ & $37-40$ & 3 & 4 & $80.70 \pm 0.92$ & $65.90^{\mathrm{a}} \pm 1.70$ & $81.74^{\mathrm{a}} \pm 2.70$ & $8.00^{\mathrm{a}} \pm 0.96$ & $10.27 \pm 2.33$ & $6^{\mathrm{a}} \pm 2.70$ \\
\hline $\mathrm{T}-4$ & $41-44$ & 1000 & 572 & $73.86 \pm 2.45$ & $57.45^{\mathrm{a}} \pm 4.00$ & $77.60^{\mathrm{a}} \pm 3.79$ & $11.15^{\mathrm{a}} \pm 1.23$ & $11.26 \pm 2.92$ & $22.41^{\mathrm{a}} \pm 3.79$ \\
\hline $\mathrm{T}-5$ & $45-48$ & 829 & 387 & $69.31 \pm 1.47$ & $46.84^{\mathrm{a}} \pm 2.46$ & $67.49^{\mathrm{a}} \pm 2.49$ & $13.16^{\mathrm{a}} \pm 1.44$ & $19.35 \pm 1.25$ & $32.52^{\mathrm{a}} \pm 2.49$ \\
\hline$T-6$ & $49-52$ & 553 & 244 & $76.28 \pm 4.12$ & $48.46^{\mathrm{a}} \pm 7.30$ & $62.60^{\mathrm{a}} \pm 6.16$ & $22.02^{\mathrm{a}} \pm 0.58$ & $15.38 \pm 5.83$ & $37.40^{\mathrm{a}} \pm 6.16$ \\
\hline $\mathrm{T}-7$ & $53-56$ & 402 & 130 & $68.18 \pm 4.06$ & $36.06^{\mathrm{c}} \pm 4.86$ & $52.61^{\mathrm{b}} \pm 5.83$ & $30.48^{\mathrm{a}} \pm 7.44$ & $16.92 \pm 3.22$ & $47.39^{b} \pm 5.83$ \\
\hline $\mathrm{T}-8$ & $57-60$ & 372 & 90 & $68.68 \pm 6.53$ & $28.17^{\mathrm{d}} \pm 14.10$ & $37.66^{\mathrm{d}} \pm 17.51$ & $49.76^{\mathrm{b}} \pm 18.29$ & $12.58 \pm 5.44$ & $62.34^{\mathrm{d}} \pm 17.51$ \\
\hline $\mathrm{T}-9$ & $61-64$ & 390 & 151 & $75.55 \pm 2.05$ & $38.02^{\mathrm{b}} \pm 4.19$ & $50.01^{\mathrm{c}} \pm 4.02$ & $25.89^{\mathrm{a}} \pm 5.03$ & $24.11 \pm 1.10$ & $49.99^{c} \pm 4.02$ \\
\hline $\mathrm{T}-10$ & $65-68$ & 304 & 137 & $76.08 \pm 3.96$ & $45.55^{\mathrm{a}} \pm 2.64$ & $60.30^{\mathrm{a}} \pm 4.35$ & $21.48^{\mathrm{a}} \pm 2.25$ & $18.22 \pm 5.94$ & $39.70^{\mathrm{a}} \pm 4.35$ \\
\hline $\mathrm{T}-11$ & $69-72$ & 222 & 112 & $76.73 \pm 0.73$ & $50.75^{\mathrm{a}} \pm 1.68$ & $66.10^{\mathrm{a}} \pm 1.60$ & $15.87^{\mathrm{a}} \pm 2.93$ & $18.03 \pm 3.10$ & $33.90^{\mathrm{a}} \pm 1.60$ \\
\hline Overall Mean & & 7452 & 2667 & $73.45 \pm 1.05$ & $47.35 \pm 2.13$ & $63.79 \pm 2.59$ & $19.98 \pm 2.45$ & $16.24 \pm 1.18$ & $36.22 \pm 2.59$ \\
\hline
\end{tabular}

\section{Summary}

The results of the present study suggested that the parental age had a significant $(P<0.01)$ influence on mean per cent total hatchability, fertile hatchability and total embryonic mortality in turkeys. Parental age did not have any significant $(p \geq 0.05)$ influence on mean per cent fertility. It can be concluded that significantly higher mean per cent total hatchability, fertile hatchability and lesser embryonic mortality were obtained from the eggs laid by turkey breeder hen during 29 to 52 and 65 to 72 weeks of age and hence, it is advisable to collect hatching eggs from 29 weeks to 52 weeks of age of turkey breeders to obtain higher hatchability performance.

\section{References}

1. King'ori AM. Review of the Factors That Influence Egg Fertility and Hatchabilty in Poultry. Int. J Poult. Sci. 2011; 10(6):483-492. 
2. Leeson S. Breeder age has unanticipated influences on the performance of their progeny. Poultry International. 2003; 42(10):36-42.

3. Koppenol A, E Delezie, Y Wang1, L Franssens, E Willems, B Ampe, et al. Effects of maternal dietary EPA and DHA supplementation and breeder age on embryonic and post-hatch performance of broiler offspring. J Anim Physiol An N. 2015; 99(1):36-47.

4. Snedecor GW, Cochran WG. Statistical methods. $8^{\text {th }}$ edition. Iowa State University Press, Ames, Iowa. U.S.A, 1994, 217.

5. Anna Anandh M, Richard Jagatheesan PN, Senthil Kumar P, Paramasivam A, Rajarajan G. Effect of Rearing Systems on Reproductive Performance of Turkey. Vet. World. 2012; 5:226.

6. Premavalli K, Omprakash AV. Effect of strain and preincubation storage period on the hatchability and embryonic mortality in turkey. Int. J Chem. Stud. 2018; 6(1):765-767.

7. Bakst Murray, Wishart G, Brillard jean pierre. Oviducal sperm selection, transport, and storage in poultry. Poult Sci Review. 1994; 5:117-143.

8. Brillard JP. Practical aspects of fertility in poultry. World Poult.Sci. 2003; 59:441.

9. Khan MJA, Khan SH, Bukhsh A, Abbass MI, Javed M. Effect of different storage period on egg weight, internal egg quality and hatchability characteristics of Fayumi eggs. Italian J. Anim. Sci. 2013; 12:211-216.

10. Tona K, Bamelis F, Coucke W, Bruggeman V, Decuypere E. Relationship between broiler breeder's age and egg weight loss and embryonic mortality during incubation in large-scale conditions. J App Poult Res. 2001; 10:221-227.

11. Ozcelik M, Cerit H, Ekmen F, Dogan I. Effect of the hatching month as an environmental factor on the hatching features of bronze turkeys. Turk J Vet Anim Sci. 2006; 30:243-249.

12. Yilmaz Dikmen, Bilgehan Sahan, Umran. The relationship among age, yolk fatty acids content, and incubation results of broiler breeders. Poult. Sci. 2009; 88:185-90. 10.3382/ps.2008-00068.

13. Okur N, Eleroglu H, M Türkoglu. Impacts of Breeder Age, Storage Time and Setter Ventilation Program on Incubation and Post-Hatch Performance of Broilers. Braz. J Poultry Sci. 2018; 2(1):027-036.

14. Latour MA, ED Peebles, SM Doyle, T Pansky, TW Smith, CR Boyle. Broiler breeder age and dietary fat influence the yolk fatty acid profiles of fresh eggs and newly hatched chicks. Poult. Sci. 1998; 77:47-53. 